\title{
Fullerenes and fullerenols survival under irradiation
}

\author{
V. A. Shilin, A. A. Szhogina, M. V. Suyasova, V. P. Sedov, V. T. Lebedev, V. S. Kozlov \\ National Research Centre "Kurchatov Institute" B. P. Konstantinov, Petersburg Nuclear Physics \\ Institute, 188300, Russia, Leningrad district, Gatchina, Orlova Roscha, Russia \\ shilin@pnpi.spb.ru
}

\section{PACS 81.05.ub}

DOI 10.17586/2220-8054-2016-7-1-146-152

\begin{abstract}
Fullerenes $\mathrm{C}_{2 n}$, endometallofullerenes Gd@ $\mathrm{C}_{2 n}, \mathrm{Gd} @ \mathrm{C}_{82}$ and water-soluble $\mathrm{Gd} @ \mathrm{C}_{2 n}(\mathrm{OH})_{38-40}$ derivatives were synthesized. These substances' survival dependences on the accumulated flux $\left(10^{16}-10^{19}\right.$ neutron $\left./ \mathrm{cm}^{2}\right)$ of neutron irradiation over a wide spectrum of energies (from thermal to fast) in the WWR-M reactor zone (Petersburg Nuclear Physics Institute) have been examined.
\end{abstract}

Keywords: fullerenes, endometallofullerenes, fullerenols, irradiation, survival.

Received: 20 November 2015

\section{Introduction}

Radiochemical technology allows the creation of new carbon-based materials and the study of their properties, stability and structure. The application of radiolabeled fullerenes, endohedral metallofullerenes (EMFs) and their water-soluble derivatives is of particular importance in modern nuclear medicine and biology, due to their potential utility as radiopharmaceuticals. Fullerene and EMF functionalization, by the attachment of different groups permits the targeted delivery of drug molecules and the use of radioactive EMF properties for diagnostic and therapeutic purposes. There are many published reviews describing endohedral fullerenes and methods for their preparation, for example [1-3].

Recent results from stability studies of endofullerenes and their water-soluble derivatives undergoing irradiation by fast and thermal neutrons in the reactor WWR-M (PNPI) are presented in this article. Non-phonon excitation mechanisms were proposed for understanding the fullerenols' interactions with fast neutrons. In particular, fast electron shaking is suggested as the most probable process $[4,5]$.

It is clear that EMFs irradiations at different neutron fields may lead to their destruction and cause the formation of new chemical substances. A molecule with daughter nucleus may also change the original chemical form leading to such instabilities as oxidation, degradation, crosslinking, etc. For example, there can be a reaction with oxygen due to ionizing radiation accompanied by the formation of reactive radical intermediates.

Although the stabilities of fullerenes and EMFs have been thoroughly investigated [6-9], the stabilities of water-soluble fullerene derivatives are less documented. This is why the present investigation is necessary.

The studies seem to be very prospective for advanced medical applications of metallofullerenes and their isotopic forms for the diagnostics (MRI) and tumor therapy. The active component (heavy metal, isotope) in such molecules is screened from surrounding tissues and toxicity risks are minimized. 


\section{Experimental and discussions}

The substances in the series $\left(\mathrm{C}_{2 n}, \mathrm{Gd} @ \mathrm{C}_{2 n}, \mathrm{Gd} @ \mathrm{C}_{82}\right.$ and $\left.\mathrm{Gd} @ \mathrm{C}_{2 n}(\mathrm{OH})_{38-40}\right)$ were synthesized for these studies. The fullerene-containing soot was produced by subjecting graphite rods to electric arc treament. Subsequently, the soot was extracted with o-xylene. The $\mathrm{C}_{2 n}$ extract's composition was determined by high-performance liquid chromatography (HPLC).

High purity (99\%) sample Gd@ $\mathrm{C}_{82}$ was extracted from soot using the solvents o-xylene and N,N-dimethylformamide (DMF). The subsequent transfer of DMF in o-xylene allows the use of chromatographic separation and final $\mathrm{Gd} @ \mathrm{C}_{82}$ purification $[10,11]$.

The Gd@ $\mathrm{C}_{2 n}$ fullerenes were isolated from soot using DMF extraction with the addition of a reducing agent to enhance the ability of the extractant. The $\mathrm{Gd} @ \mathrm{C}_{2 n}$ obtained in this manner was the initial compound to yield the hydroxylated $\mathrm{Gd} @ \mathrm{C}_{2 n}(\mathrm{OH})_{38-40}$ sample in dilute aqueous hydrogen peroxide solution at $65^{\circ} \mathrm{C}$. According to X-ray fluorescence analysis (XRF), water-soluble fullerenols contained $4.8 \mathrm{wt} \%$ of gadolinium. The number of hydroxyl groups in a fullerenol molecule $(\mathrm{x}=38-40)$ was determined gravimetrically (thermal analysis [12]). The resulting product contained 55\% of the gadolinium component according to calculation based on the $\mathrm{Gd} @ \mathrm{C}_{82}(\mathrm{OH})_{38}$ formula.

The powder samples were soldered in quartz ampules and irradiated for $0.5-32 \mathrm{~h}$ in integral flux of up to $10^{19}$ neutrons $/ \mathrm{cm}^{2}$ in the WWR-M. The temperature in the reactor channel was $70{ }^{\circ} \mathrm{C}$.

The irradiated samples stability was determined as follows: the water soluble Gd@ $\mathrm{C}_{2 n}(\mathrm{OH})_{38-40}$ was dissolved in a determined volume of water, assuming the previouslydetermined solubility. The solution was then stirred for $4 \mathrm{~h}$ at $25^{\circ} \mathrm{C}$ and was then centrifuged. Irradiated $\mathrm{C}_{2 n}, \mathrm{Gd} @ \mathrm{C}_{2 n}$ and $\mathrm{Gd} @ \mathrm{C}_{82}$ samples were dissolved in o-xylene and stirred for $24 \mathrm{~h}$. The insoluble precipitates were dried and weighted. The differences between the $\mathrm{C}_{2 n}$ original weights and the insoluble portions, normalized to the initial weights provided product stability data. The stability was defined for the $\mathrm{Gd} @ \mathrm{C}_{2 n}(\mathrm{OH})_{38-40}, \mathrm{Gd} @ \mathrm{C}_{2 n}$ and $\mathrm{Gd} @ \mathrm{C}_{82}$ samples as the radioactivity ratio for the soluble and insoluble portions.

A Shimadzu LC-20 HPLC with Lab Solutions software and system for data processing and output analysis was used for both analysis and separation. The fullerene fractions separation and final purification were performed using three types of chromatographic columns: a BuckyPrep $4.6 \times 250 \mathrm{~mm}$ analytical column, a Buckyrep $10 \times 200 \mathrm{~mm}$ semi-prep column, and a Buckyrep $10 \times 200 \mathrm{~mm}$ semi-prep column. Pure toluene was used as a mobile phase (eluent) in standard analyses. The peaks were detected by the absorption at $330 \mathrm{~nm}$.

Mass-spectrometric analysis of the high-purity Gd@ $\mathrm{C}_{82}$ sample was performed with a Varian Fourier transform ion cyclotron resonance mass spectrometer and with an Ultraflextreme device (Bruker), respectively. The Gd@ $\mathrm{C}_{82}$ sample spectra were recorded at standard device tuning $(500-4500 \mathrm{Da})$ without the use of a matrix. The positive ions were recorded at a minimal laser power near the ion appearance threshold, so as to suppress the possible fragmentation. The obtained mass-spectrum is shown in Fig. 1.

Chemical bonding information on the hydroxyl groups was obtained using Fourier transform infrared spectroscopy (FTIR). The measured product FTIR-spectrum showed characteristic frequencies corresponding to chemical bonds in fullerenols. The spectrum is dominated by a broad band at $3412 \mathrm{~cm}^{-1}$, presumably due to the stretching mode of the $\mathrm{OH}$-groups, as well as other peaks at $1620 \mathrm{~cm}^{-1}(\mathrm{C}=\mathrm{C}), 1390 \mathrm{~cm}^{-1}$ and $1150 \mathrm{~cm}^{-1}(\mathrm{C}-\mathrm{OH})$.

The $\gamma$-spectra were recorded using a semiconductor spectrometer with a detector based on high-pure germanium HPGe (Ortec, EG \& G) as done in previous work [13]. The detector 


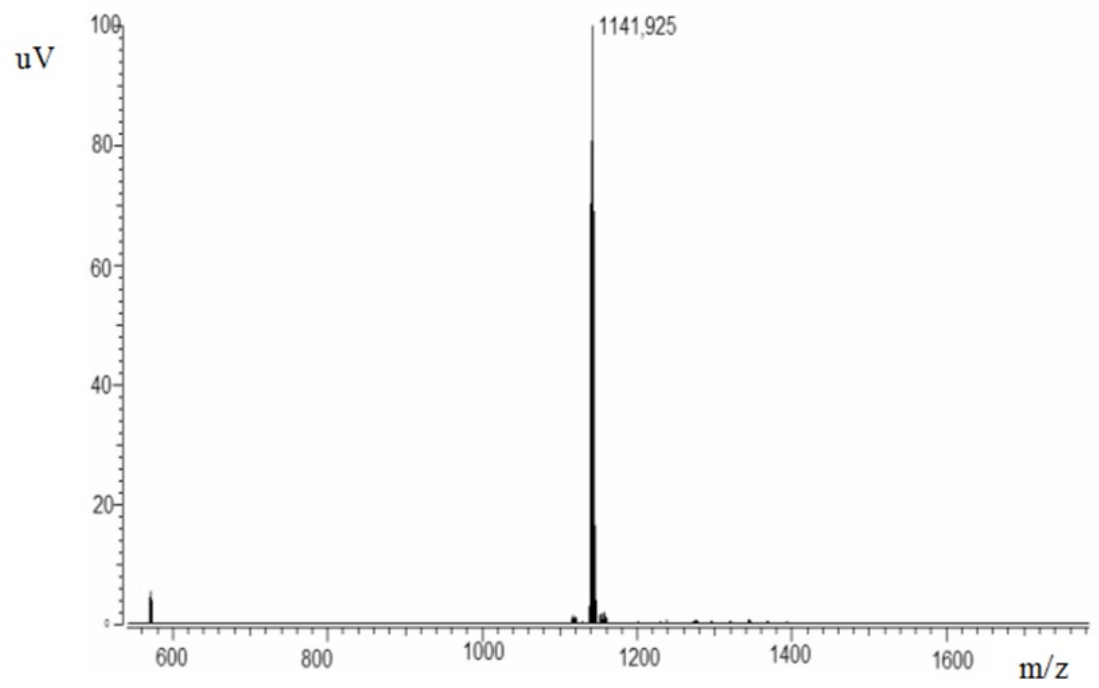

FIG. 1. Mass-spectrum of Gd@ $\mathrm{C}_{82}$, Varian mass-spectrometer

efficiency for the $1 \mathrm{MeV}$ range was $5 \%$. Resolution for $122.06 \mathrm{keV} \gamma$-line of ${ }^{57} \mathrm{Co}$ was $0.57 \mathrm{keV}$. The diameter of the detector was $25 \mathrm{~mm}$ and the thickness was $13 \mathrm{~mm}$.

The stability dependence of $\mathrm{C}_{2 n}, \mathrm{Gd} @ \mathrm{C}_{2 n}, \mathrm{Gd} @ \mathrm{C}_{82}, \mathrm{Gd} @ \mathrm{C}_{2 n}(\mathrm{OH})_{38-40}$ upon irradiation time is shown in Fig. 2.

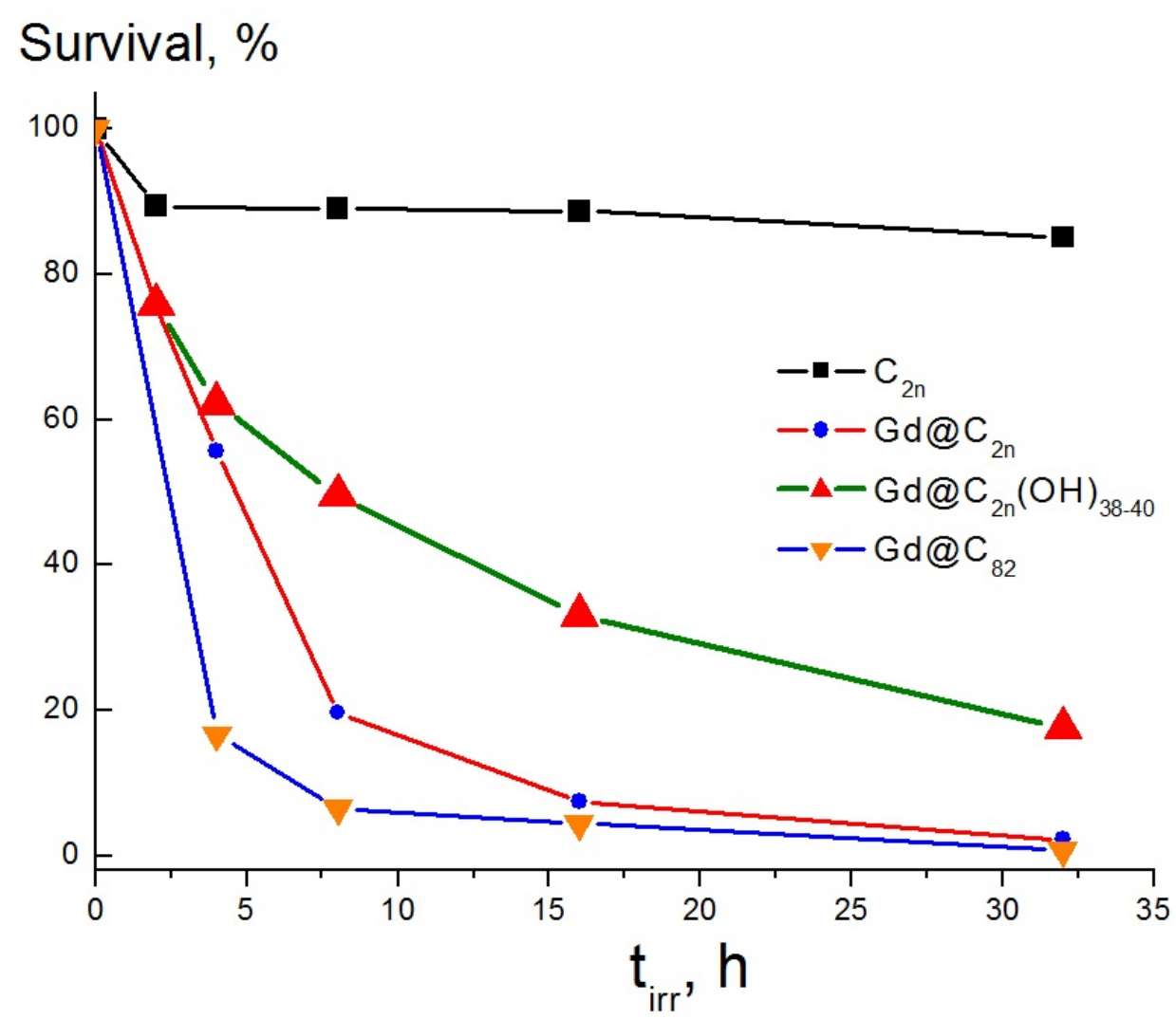

FIG. 2. The fullerenes and fullerenols stability dependence upon irradiation time at an integral flux of $8 \cdot 10^{13}$ neutron $/ \mathrm{s} \cdot \mathrm{cm}^{2}$ 
As it can be seen in Fig. 2, the $\mathrm{C}_{2 n}$ fullerenes have the higher survival as compared with others. It is no wonder, since the $\mathrm{C}_{2 n}$ composition (Fig. 3) contains predominantly $\mathrm{C}_{60}$ and $\mathrm{C}_{70}$ [14] possessing a high survival.

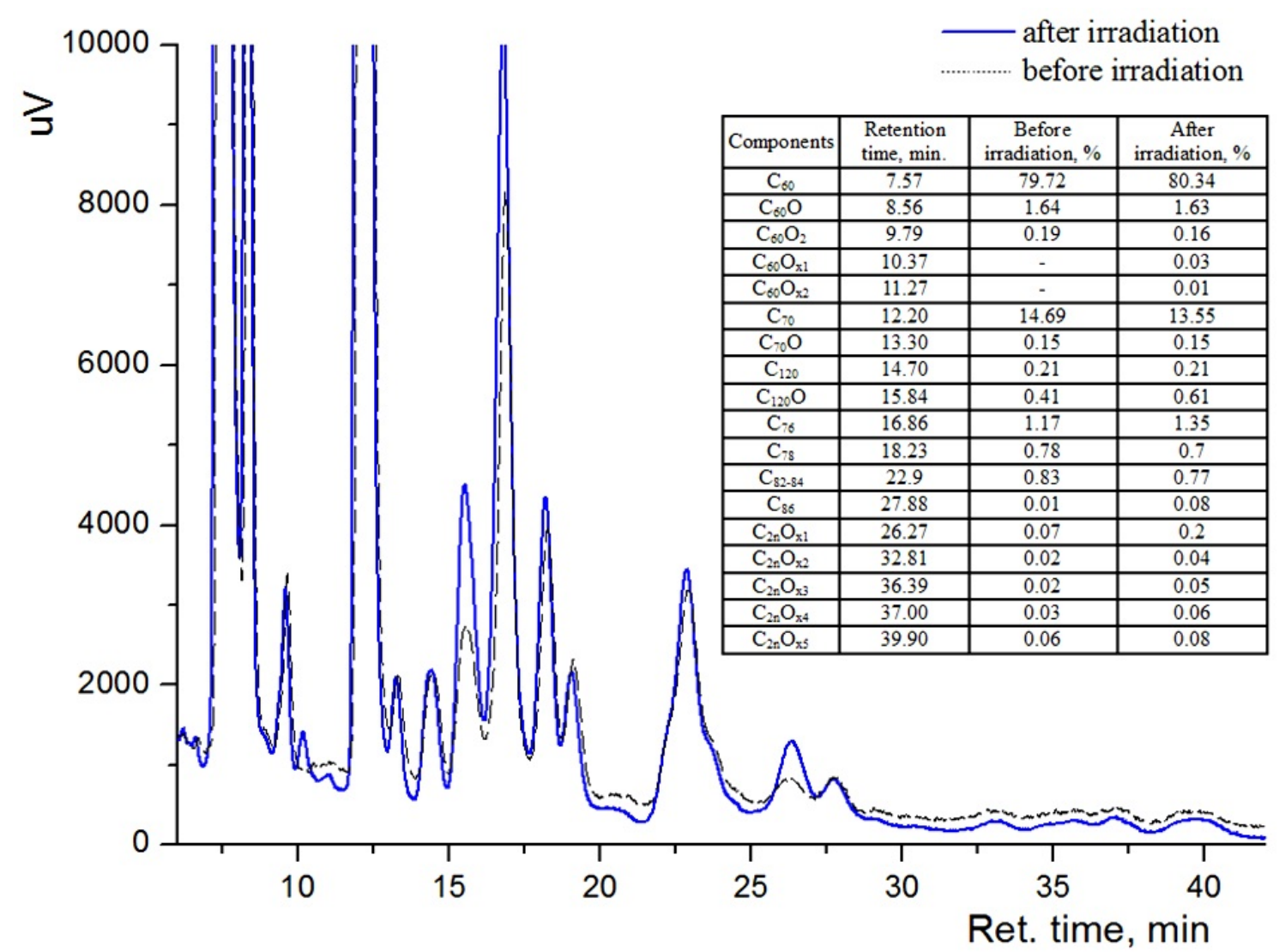

FIG. 3. Fullerenes $\mathrm{C}_{2 n}$ chromatogram

Meanwhile, the $\mathrm{Gd} @ \mathrm{C}_{2 n}(\mathrm{OH})_{38-40}$ has shown a higher survival compared with $\mathrm{Gd} @ \mathrm{C}_{2 n}$ and $\mathrm{Gd} @ \mathrm{C}_{82}$. This stability of fullerenol can be interpreted as the effect of its shell containing $\mathrm{OH}$-groups and absorbed water. Really thermal neutrons undergo very intense incoherent scattering on the protons in the shell of fullerenol that prevents neutron absorption by the gadolinium atoms and the subsequent cage destruction due to recoil.

$\mathrm{Gd} @ \mathrm{C}_{2 n}$ survives better than $\mathrm{Gd} @ \mathrm{C}_{82}$, because it contains mainly $\mathrm{C}_{60}$ which has a more stable framework and lower amounts of higher fullerenes such as $\mathrm{C}_{82}$. This testifies to the fact that the main reason for EMF destruction is a result of the Szilard-Chalmers reaction.

The high survival of Gd@ $\mathrm{C}_{2 n}$ sample as compared to Gd@ $\mathrm{C}_{82}$ can be associated with a difference in metal atom localization inside the carbon cage, with the electron-donating properties of the surrounding molecular environment and etc. It is known that the EMF properties are strongly dependent upon the metal atom's position inside the carbon cage. It has been noted that even a slight shift inside the carbon atom framework can lead to significant changes in the EMF's molecular properties [15-18].

It should be noted, there is a substantial charge transfer between Gd and the nearest carbon atoms in a Gd@ $\mathrm{C}_{82}$ molecule. This value was found to be almost 2.5 times higher than in La@ $\mathrm{C}_{82}$ molecule [19]. Such a high charge density suggests a strong bonding for Gd with the nearest carbon atoms (i.e. covalent bonds). Obviously, this circumstance makes the molecule $\mathrm{Gd} @ \mathrm{C}_{82}$ and $\mathrm{Gd} @ \mathrm{C}_{2 n}$ more resistant to various physical and chemical, and, in our opinion, 
radiation effects. It should be noted that the charge transfer of $\mathrm{Gd}$, and $\mathrm{La}$ are drastically different, even though they have very similar oxidation potentials $\mathrm{Mo}^{0} / \mathrm{M}^{3+}(-2.4 \mathrm{~V})$. It is known that with such potential lanthanides donate three electrons to the fullerene cage and become trivalent.

In EMF molecules and their derivatives [20-22] the electron structure is modified not only via an internal charge transfer but also due to exterior effects, for example, by the presence of attached hydroxyl groups. For fullerenes, EMF and fullerenols such a combination makes the treatment of their resistance to irradiation very complicated and dependent on molecular symmetry, size, carbon framework electronic structure, the atom's localization inside a carbon cage, the atom's recoil energy, and at last on the presence of impurities and damage in the irradiated material.

It is worth noting that except for destruction, the irradiation may induce opposite processes, i.e. a synthesis of some molecular forms. When the recoil high-energy metal atom can leave molecule and then collide with other molecules to destroy them, this recoil energy of the atom is reduced and it can insert itself into another carbon cage, thus creating a new EMF.

Table 1 shows some previously obtained endometallofullerenols' stability data under different conditions. Such factors are the samples' composition, the metal atom radius, the nuclear recoil energy upon neutron capture. Although the various factors cumulative effect greatly smoothes, the presence $\mathrm{C}_{2 n}(\mathrm{OH})_{x}$ fullerenol influence apparently predominates.

TABLE 1. The endometallofullerenols survival dependence from different factors [23]

\begin{tabular}{|c|c|c|c|c|c|}
\hline \multirow{2}{*}{ Element } & \multicolumn{2}{|c|}{ Mixture content, \% } & Atom radius, & $\begin{array}{c}\text { Recoil energy, } \\
\mathrm{eV}\end{array}$ & Survival, \% \\
\cline { 2 - 5 } & $\mathrm{M} @ \mathrm{C}_{2 n}(\mathrm{OH}) x$ & $\mathrm{C}_{2 n}(\mathrm{OH}) x$ & 181 & 237 & 85 \\
\hline $\mathrm{Sm}^{* *}$ & $17\left(\mathrm{Sm} @ \mathrm{C}_{2 n}\right)$ & $83\left(\mathrm{C}_{2 n}\right)$ & 180 & 136.1 & 52 \\
\hline $\mathrm{Tb}$ & 81 & 19 & 179 & 136.4 & 94.1 \\
\hline $\mathrm{Gd}$ & 60 & 40 & 162 & 894.1 & 82.5 \\
\hline $\mathrm{Sc}$ & 95 & 5 & 126 & 393.3 & 47.0 \\
\hline $\mathrm{Fe}$ & 97,6 & 2,4 & 139 & 123.0 & 87.2 \\
\hline $\mathrm{Mo}$ & 12 & 88 & 182 & 126.9 & 45.0 \\
\hline $\mathrm{Pr}$ & 70 & 30 & - & - & 85 \\
\hline $\mathrm{C}_{2 n}$ & - & 100 & & & \\
\hline
\end{tabular}

${ }^{*}$ The samples irradiation are proceeded during $8 \mathrm{~h}$ in the integral flux $8 \cdot 10^{13}$ neutron $/ \mathrm{s} \cdot \mathrm{cm}^{2}$.

** The sample Sm@ $\mathrm{C}_{2 n}$ survival is shown for comparison. The irradiation are proceeded during $2 \mathrm{~h}$ in the integral flux $8 \cdot 10^{13}$ neutron $/ \mathrm{s} \cdot \mathrm{cm}^{2}[24]$.

Another feature of endometallofullerenols behavior under neutron irradiation is the relatively high stability value as compared to the EMF. As it is seen from Table 1, all fullerenols showed significantly greater stability (from 45 to $94 \%$ ) than the corresponding $\mathrm{M} @ \mathrm{C}_{2 n}$ (from 15 to $20 \%$ ). We expected to obtain similar results for irradiated $\mathrm{C}_{60}, \mathrm{C}_{70}$ fullerenes and $\mathrm{C}_{60}(\mathrm{OH})_{x}, \mathrm{C}_{70}(\mathrm{OH})_{x}$ water-soluble derivatives [14]. However, comparison of the stabilities of $\mathrm{C}_{60}, \mathrm{C}_{70}$ with their water-soluble derivatives of $\mathrm{C}_{60}(\mathrm{OH})_{x}, \mathrm{C}_{70}(\mathrm{OH})_{x}$ shows that fullerenol survival decreases by $2-3$ times under $32 \mathrm{~h}$ irradiation as compared with fullerenes. Fullerenol molecules under irradiation lose some of the hydroxyl groups and are not destroyed, becoming insoluble. The soluble part weight reduces. The soluble and insoluble parts comparison becomes incorrect. Therefore additional investigations are nesessary. 
Previously investigated samples $\mathrm{M} @ \mathrm{C}_{2 n}(\mathrm{M}=\mathrm{Sc}, \mathrm{La}, \mathrm{Nb}, \mathrm{Sm}, \mathrm{Eu}, \mathrm{Tb}, \mathrm{Ho}, \mathrm{Yb}, \mathrm{Tm}$, $\mathrm{Lu}, \mathrm{Pr}, \mathrm{Fe}, \mathrm{Mo}, \mathrm{Gd})$ have shown the average survival from 15 to $20 \%$ except Sm@ $\mathrm{C}_{2 n}$ and Gd@ $\mathrm{C}_{2 n}$ [24]. As mentioned earlier, a Gd@ $\mathrm{C}_{2 n}$ high stability to reactor neutron irradiation can be explained by an abnormal feature of Gd-endohedral fullerene's electronic structure. The high stability of $\mathrm{Sm} @ \mathrm{C}_{2 n}$ can also be explained in such a way. To determine the anomalous features of how the bivalent $\mathrm{Sm}^{+2} @ \mathrm{C}_{2 n}^{-2}$ differs from $\mathrm{Gd}^{+3} @ \mathrm{C}_{2 n}^{-3}$, additional investigations are nesessary. Although one should bear in mind that under certain circumstances, the bivalent $\mathrm{Sm}^{+2}$ can be transformed into trivalent $\mathrm{Sm}^{+3}$ [25].

\section{Conclusion}

The $\mathrm{C}_{2 n}$ fullerenes, Gd@ $\mathrm{C}_{82}, \mathrm{Gd} @ \mathrm{C}_{2 n}$ endofullerenes and $\mathrm{Gd} @ \mathrm{C}_{2 n}(\mathrm{OH})_{38-40}$ watersoluble derivatives were synthesized, purified and a comparative analysis of their stabilities under neutron irradiation has been performed at the PNPI WWR-M reactor.

Various factors have defined the fullerenes' and fullerenols' stability to neutron irradiation; among these factors are the Szilard-Chalmers reactions and electronic structural features which give the largest contribution to these compounds' destruction.

The survival of water-soluble Gd-fullerenol was found to be an order of magnitude greater than that of the original EMF which is of substantial importance, assuming fullerenols' biomedical applications as advanced isotopic preparations.

In general, the investigation of fullerenes and fullerenols behaviors under irradiation carries not only theoretical but predominantly practical interests, since the knowledge of their radiation resistance offers a suitable option for a variety of the aforementioned biomedical applications.

\section{Acknowledgements} ofi_m).

The work was supported by Russian Foundation for Basic Research (grant 14-23-01015

\section{References}

[1] Popov A.A., Yang S., Dunsch L. Endohedral Fullerenes. Chem. Rev., 2013, 113(8), P. 5989-6113.

[2] Gan L., Yang D., Zhang Q., Huang H. Preparation of open-cage fullerenes and incorporation of small molecules through their orifices. Adv. Mater., 2010, 22, P. 1498-1507.

[3] Gan T., Hu C., Hu S. Preparation of graphene oxide-fullerene/phosphotungstic acid films and their application as sensor for the determination of cis-jasmone. Anal. Methods, 2014, 6, P. 9220-9227.

[4] Grushko Yu.S., Khodorkovski M.A., Kozlov V.S., Kolesnik S.G., Shilin V.A., Grachev S.A., Artamonova T.O. Radioactive Metallofullerenes: Hot Atom Chemistry Aspects. Fuller., Nanotub. Carbon Nanostr., 2006, 14, P. 249-259.

[5] Averbukh V., Cederbaum L.S. Interatomic electronic decay in endohedral fullerenes. Phys. Rev. Lett., 2006, 96, P. 401-405.

[6] Sueki K., Akiyama K., Zhao Y. L., Ito I., Ohkubo Y., Kikuchi K., Katada M., Nakahara H. Systematic study of lanthanoid endohedral metallofullerenes: Production yields, HPLC retention time and reactor irradiation effects. J. Radioanalytical Nuclear Chem., 2003, 255(1), P. 159-164.

[7] Sueki K., Kikuchi K., Tomura K., Nakahara H. Stability of metallofullerenes following neutron capture reaction on the metal ion. J. Radioanal. Nucl. Chem., 1998, 234, P. 95-100.

[8] Sueki K., Akiyama K., Kikuchi K., Nakahara H., Tomura K. Stability of Radio-Metallo-Fullerene against Beta-Decay. J. Radioanal. Nucl. Chem., 1999, 239(1), P. 179-185.

[9] Nakahara H., Sueki K., Sato W., Akiyama K. Nuclear reactions and radionuclides in study of fullerenes. $J$. Radioanal. Nucl. Chem., 2000, 243(1), P. 169-179. 
[10] Kozlov V.S., Suyasova M.V., Lebedev V.T. Synthesis, Extraction, and Chromatographic Purification of Higher Empty Fullerenes and Endoghedral Gadolinium Metallofullerenes. Russian J. Appl. Chem., 2014, 87(2), P. 121-127.

[11] Suyasova M.V., Kozlov V.S. Synthesis and Chromatographic Study of Higher Empty Fullerenes and Endometallofullerenes in solutions. Communication of PNPI 2941. Gatchina, 2014. 20 p. (Rus.).

[12] Goswami T.H., Singh R., Alam S., Mathur G.N. Thermal analysis: a unique method to estimate the number of substituents in fullerene derivatives. Thermochimica Acta, 2004, 419, P. 97-104.

[13] Grushko Yu.S., Alekseev E.G., V.V. Voronin et. al. Tracer Study of Smx@C $\mathrm{C}_{2 n}$. Mol. Mat., 2006, 7, P. $115-118$.

[14] Shilin V.A., Lebedev V.T., Sedov V.P., Szhogina A.A. Fullerenes and their derivatives synthesis and radiation resistance. Crystallography (in press, Rus.).

[15] Suenaga K., Iijima S., Kato H., Shinohara H. Fine-structure analysis of Gd M45 near-edge EELS on the valence state of Gd@C $\mathrm{C}_{82}$ microcrystals. Phys. Rev. B, 2000, 62(3), P. 1627-1630.

[16] Nishibori E., Takata M., Sakata M., Tanaka H., Hasegawa M., Shinohara H. Giant motion of La atom inside $\mathrm{C}_{82}$ cage. Chem. Phys. Lett., 2000, 330, P. 497-502.

[17] Nishibori E., Takata M., Sakata M., Inakuma M., Shinohara H. Determination of the cage structure of Sc@ $\mathrm{C}_{82}$ by synchrotron powder diffraction. Chem. Phys. Lett., 1998, 298, P. 79-84.

[18] Takata M., Imeda B., Nishibori E., Sakata M., Saito Y., Ohno M., Shinohara H. Confirmation by X-raydiffraction of the Endohedral Nature of the Metallofullerene Y@C 82 . Nature, 1995, 377, P. 46-49.

[19] Nishibori E., Iwata K., Sakata M., Takata M., Tanaka H., Kato H., Shinohara H. Anomalous endohedral structure of Gd@C 82 metallofullerenes. Phys. Rev. B, 2004, 69, P. 113412(1-4).

[20] Tang J.X., Yuan G.M., Cao H., et. al. Tuning electronic properties of metallic atom in bondage to a nanospace. J. Phys. Chem., 2005, 109, P. 8779-8785.

[21] Starke K., Navas E., Arenholz E., Hu Z., Baumgarten L., van der Laan G., Chen C. T., Kaindl G. Magnetic circular dichroism in $4 \mathrm{~d} \rightarrow 4 \mathrm{f}$ resonant photoemission and photoabsorption of Gd metal. Phys. Rev. B, 1997, 55, P. 2672-2675.

[22] Tobin J.G., Chung B.W., Schulze R.K., Terry J., Farr J. D., Shuh D. K., Heinzelman K., Rotenberg E., Waddill G.D., Van der Laan G. Resonant photoemission in f-electron systems: Pu and Gd. Phys. Rev. B, 2003, 68, P. $115109(1-11)$.

[23] Szhogina A.A., Shilin V.A., Sedov V.P., Lebedev V.T. Endohedral metallofulerenols survival under neutron irradiation. Crystallography (in press, Rus.).

[24] Shilin V.A., Lebedev V.T., Kolesnik S.G., Kozlov V.SGrushko., Yu.S., Sedov V.P., Kukorenko V.V. Investigation of the Neutron Activation of Endohedral Rare Earth Metallofullerenes. Crystallography Reports, 2011, 56(7), P. 1192-1196.

[25] Okazaki T., Lian Y., Gu Z., Suenaga K., Shinohara H. Isolation and spectroscopic characterization of Smcontaining metallofullerenes. Chem. Phys. Lett., 2000, 320, P. 435-440. 